\title{
The Chinese School, Global Production of Knowledge, and Contentious Politics in the Disciplinary IR
}

\author{
Yongjin Zhang \\ University of Bristol
}

\begin{abstract}
Chinese studies of International Relations constitute today an integral part of the claim of IR as a global discipline. This paper starts by providing a critical evaluation of the contribution made by the so-called 'Chinese School of IR' to the global production of knowledge. Against this background, it teases out a curious case of 'schools of IR' as commonly labelled in the global IR theoretical conversation and looks at how such labels have been used by the 'core' to create a parallel but explicitly inferior universe of knowledge production to localize theoretical noises from the 'peripheries'. Situating the Chinese School of IR in such global context, it considers how 'school' label has been proactively appropriated by Chinese scholars to engage in a purposely contentious politics in the disciplinary IR, which questions the claim of the American 'core' as the creator, depositor, and distributor of universal knowledge, and seeks to unveil the geo-historical linkage between the political and the epistemic. School labelling therefore matters, it is argued, because it has become a site of contestation of geopolitics of knowledge and reflects the perils and promises in our collective pursuit of constructing a truly global IR.
\end{abstract}

Keywords: The Chinese School, global IR, knowledge production, theoretical conversation, contentious politics

\section{Introduction}

At its centenary, International Relations (IR) can genuinely claim to be a global academic discipline. This is in sharp contrast to the disciplinary status of IR fifty years ago as evaluated in The Aberystwyth Papers. ${ }^{1}$ Evidence of the institutionalized globality of IR as a discipline is everywhere around us in terms of 1 . subjects taught and research degrees offered at Universities around the world; 2 . academic and policy-related journals dedicated to the subject of International Relations published in different countries all over the world; 3. research monographs and books published in all different languages globally; 4. unprecedented global flow of everyday knowledge exchange in cyber space and through other means; and 5. global contribution to the production of IR knowledge. Whether there is a purported global IR or not is, however, altogether a different question. The intellectual hegemony of the Western (trans-Atlantic) IR is arguably still largely intact. There is a discernible core and periphery relationship in the global production of knowledge. The calls for 'worlding beyond the West'

Yongjin Zhang, Professor of International Politics, University of Bristol, UK. Email: yongjin.zhang@bristol.ac.uk. (D) 00000002-3650-0934.

Brian Porter, ed., Aberystwyth Papers: International Politics, 1919-69 (Oxford: Oxford University Press, 1972). 
and for the production of non-Western and post-Western IR scholarship only emphasize daunting challenges posed by geopolitics of knowledge in constructing a truly global IR. ${ }^{2}$

This paper discusses IR disciplinary growth in China over the last forty years as constitutive of the globalization of IR as an academic discipline. It provides first some reflections on the disciplinary growth of IR in China and the intellectual engagement between the Chinese and the global IR epistemic communities over the last forty years. This is followed by a critical assessment of the contribution made by the purported Chinese School of IR to global production of knowledge and conscious efforts of Chinese scholars at theoretical innovation and local production of global knowledge. Reflecting on the social contentions on and ongoing debates about the Chinese School of IR, it considers the 'School' labelling as a site of contestation for geopolitics of knowledge and reflects on the perils and promises of contentious politics for our collective pursuit of a truly global IR.

\section{IR in China at Forty: Some Reflections}

IR as an academic discipline and distinct intellectual activity is relatively new in China. At the beginning of the opening and reform in 1979, disciplinary IR as we understand today was virtually non-existent in China. ${ }^{3}$ Over the last forty years, enduring efforts have been made to construct IR as an academic discipline in China with increasingly intensified intellectual engagement with the global IR epistemic community. IR in China today is a well- established and thriving academic discipline. There is in the first instance the proliferation of university departments on international studies as well as vibrant development and institutionalization of research agenda and teaching curriculums, ${ }^{4}$ so much so that it is claimed recently that the academic excellence achieved by some post-1980s Chinese scholars is better than that of Ph.D. scholars trained in European universities, thanks to the internationalization of IR teaching and research in China. ${ }^{5}$ Also noteworthy is the dramatic growth of research institutes and think tanks for international studies and foreign policy matters both at the national and provincial levels and in numerous universities, in addition to those under the umbrella of the Chinese Academy of Social Sciences. ${ }^{6}$ The scholarly community of Chinese IR has become arguably one of the most dynamic and certainly the fastest growing national branch of global IR epistemic community, both in terms of the number of researchers, and increasingly, in terms of the output of publications. With the emergence of a self-conscious

\footnotetext{
2 Amitav Acharya, "Global International Relations (IR) and Regional Worlds: A New Agenda for International Studies," International Studies Quarterly 58, no. 4 (2014): 647-59; Amitav Acharya and Barry Buzan, "Why Is There No Non-Western IR Theory?," International Relations of the Asia-Pacific 7, no. 3 (2007): 287-312; Amitav Acharya and Barry Buzan, "Why is there no Non-Western International Relations Theory? Ten years on," International Relations of the Asia- Pacific 17, no. 3 (2017): 341-70; Arlene Tickner and Ole Waever, eds., International Relations Scholarship around the World (London and New York: Routledge, 2009); Arlene Tickner and David Blaney, eds., Thinking International Relations Differently (London and New York: Routledge, 2012).

A number of notable signposts in the disciplinary growth of IR in the 1980s are noted recently by Yan Xuetong (2018). Peking University started to recruit postgraduate students in international studies only in 1978; the first in China. The first article that introduced Western IR theory to China was published only in 1981. The first batch of academic positions dedicated to IR appeared in Chinese universities no earlier than 1983. It was not until 1985 that the first translated book about IR theory was published in China. The first national IR theory conference was held in Shanghai only in 1987.

4 Yaqing Qin, "Why is There No Chinese IR Theory," International Relations of the Asia-Pacific 7, no. 3 (2007): 313-40; David Shambaugh, "International Relations Studies in China Today: History, Trends and Prospects." International Relations of the Asia-Pacific 11, no. 3 (2011): 339-72.

5 Xuetong Yan, "Academic Research on International Relations in the Last Forty Years since the Beginning of Economic Opening and Reform,” (2018), http://www.aisixiang.com/data/114932.html. 
epistemic community of IR and the growing regional and global networks of IR scholars working in China, the intellectual world of Chinese IR has changed dramatically over the last forty years. ${ }^{7}$

This rigorous and dramatic disciplinary growth of IR in China must be understood and appreciated against a set of historically contingent circumstances out of which it precariously began. In the first place, it is changing political circumstances in the post-Mao China, particularly the opening and reform launched in December 1978 dubbed as China's 'second revolution'. It is the 'burying of Mao', metaphorically, that proved decisive in the emancipation of the mind in China and in creating intellectual space and securing institutional opportunities for the disciplinary IR to take roots, arguably for the first time, in China. ${ }^{8}$ The growth of disciplinary IR, however, still has to battle with often repressive political and intellectual conditions, (self-)censorship and political control under an authoritarian government which are not always conducive to the production of knowledge. It has also been deeply entangled with complex policy needs and national interests of a rising China.

Secondly, between 1949 and 1979, revolutionary China amounted to, in the words of a prominent Chinese scholar, 'a desert of social sciences'. Little genuine social science research existed in those years. Following the Soviet model in higher education, in Chinese universities, disciplinary destruction rather than disciplinary construction in social sciences was the order of the day. This cannot be accounted only by the devastation of the Cultural Revolution, when all Chinese universities and research institutes were either closed down, or stopped operating at their full capacity, for a decade. Even more devastating perhaps is the near-total intellectual insulation of Chinese scholars from the disciplinary development in and dialogue with the West in almost all social science disciplines between 1949 and 1979, when no meaningful intellectual conversation took place largely as a consequence of China's alienation from international society, when revolutionary China lived in 'angry isolation'. For all intents and purposes, when the 'paradigm wars' in IR started with the publication of Kenneth Waltz's Theory of International Politics in 1979 in the United States, there was virtually no direct 'professional communication' between Chinese and Western scholars in political science and IR. The intellectual world of Chinese IR, if any, was a terra incognita of the disciplinary IR flourishing in the West then.

1979 opened, therefore, great opportunities for Western IR to expand into and claim the Chinese disciplinary world of IR as a terra incognita and for the Chinese construction of IR as an academic discipline in China. It is, however, the personal intervention of Deng Xiaoping, China's would-be paramount leader, that enabled Chinese and Western scholars collectively to take up these opportunities, rendering possible the global expansion of IR into China. In a speech made on 30 March 1979 at the Party's theoretical works meeting, Deng remarked,

\footnotetext{
7 Jisheng Sun, "IR Theoretical Development in China since the Beginning of Economic Reform and Opening: Discourses, Practices and Innovation," World Economics and Politics 8 (2018): 4-29.

8 Yan, "Academic Research".

9 Yongjin Zhang, China in International Society since 1949: Alienation and Beyond (Basingstoke: Palgrave, 1998)
} 
We have neglected for many years research of political science, law, sociology as well as world politics. We need to catch up now in a timely manner. We have admitted that we lag behind the West in natural sciences. We should also admit that we also lag behind the West in social sciences. ${ }^{10}$

This is the third historically contingent circumstance. The growth of disciplinary IR in China started understandably from an active learning process focused on knowledge acquisition from the existing scholarship produced mostly in the West. The sharp learning curve of Chinese IR, perhaps unsurprisingly, has been overwhelmingly influenced by IR scholarship from the United States. This was a period when 'a romantic view of the West dominated, and scholars copied Western scholarship without much regard for Chinese perspectives and ideas'. ${ }^{11}$ By one account, 85 key theoretical works in English that have been translated into Chinese were published by five major presses in China by March 2007, more than $90 \%$ of which are American. Like other national IR scholarly communities around the world, scholars in the emerging Chinese IR epistemic community 'follow the American debates and teach American theories'. ${ }^{12}$ The internalization of the American IR theoretical discourse in China (or to put it differently, the colonization of Chinese IR's intellectual terrain) can perhaps best be illustrated by the fact that even Chinese academic debates on the prospect of China's peaceful rise was originally 'structured around the three mainstream IRTs' ${ }^{13}$ Self-identified Chinese realists, Chinese liberals and Chinese constructivists grappled among themselves with the question of whether China's peaceful rise is possible, largely reproducing the same debate as in the United States.

The bitter-sweet irony of this engagement is that while the growth of disciplinary IR in China has helped this 'not so international' discipline go global, it has not produced a global IR that is in any manner inclusive of Chinese voices, experiences and knowledge claims. Rather, it has produced and reproduced an asymmetric core and periphery structure of communication in this highly stratified discipline. In so doing, the growth of disciplinary IR in China has conceded to American intellectual hegemony and self-marginalized, perhaps unwittingly, Chinese voices, knowledge claims and ambition for theoretical innovation. Yet, it is from the margins of the globalized discipline that Chinese IR scholars have launched fierce contestations to, if not a revolt against, the intellectual hegemony of Western IR theories. Such assertions from the margins are undoubtedly aimed at seeking the recognition of knowledge claims made by Chinese scholars in the globalized discipline still dominated by the West. However, in making conscious efforts to find their own voices and to bring Chinese tradition to bear on the understanding and theorization of IR, Chinese scholars, through these contestations, have already begun to address a number of concerns on what Amitav Acharya calls 'a new agenda of international studies', contributing to facilitating

${ }^{10}$ Xiaoping Deng, Selected Works of Deng Xiaoping, Volume II (Beijing: People's Publishing House, 1994), 180-81. 105 .

1 Yiwei Wang, "China: Between Copying and Constructing," in Tickner and Waever, International Relations Scholarship,

${ }_{12}$ Ole Waever, "The Sociology of a Not So International Discipline: American and European Developments of Internationa Relations," International Organization 52, no. 4 (1998): 723.

13 Yaqing Qin, "Development of International Relations Theory in China: Progress through Debates," International Relations of the Asia-Pacific 11, no. 2 (2011): 246. 
the emergence of a 'Global IR' as 'a truly inclusive discipline, recognizing its multiple and diverse foundations'. ${ }^{14}$

As I have argued somewhere else, the diffusion of Western IR has played a constitutive role in the disciplinary growth of Chinese IR and in the making of Chinese international theory. The long march to theoretical innovation in Chinese IR is accompanied by sustained Chinese intellectual engagement with trans-Atlantic IR as complex social processes of change that have brought into being the intellectual world of Chinese IR. More specifically, I have highlighted three epistemic turns in the IR disciplinary growth in China in terms of local knowledge production, namely, from epistemic ignorance to epistemic optimism, from epistemic optimism to epistemic scepticism, and from epistemic scepticism to epistemic reflexivity, in these long social processes. It is the latest epistemic turn to purposive reflexivity, it is argued, that has led to promising indigenous production of knowledge in China, as international studies in China have moved decisively from simply knowledge acquisition to knowledge production/creation. ${ }^{15}$

The rapid rise of China and China's changing role in global politics, in this reading, provides stimulus for the latest epistemic turn in Chinese IR in three ways. It accentuates Chinese scholars' awareness of the deficiency of the explanatory power of existing transAtlantic IR theories. It makes it imperative to have a theoretical construct and research agenda that cater to understanding a rising China's strategic challenges and meeting the policy needs of a rising power. It has provided central empirical problems and analytical puzzles to theorize IR from a distinctive Chinese perspective, among which are China's changing identity in global politics, its integration into international society, and the prospect of its peaceful rise. ${ }^{16}$ One could add also the question of the legitimacy of rising Chinese power and therefore also the legitimacy of the post-American liberal global order. ${ }^{17}$ To the extent that IR theory constructs the world that it purports to describe and is constitutive of the reality that it addresses, to paraphrase Acharya and Buzan, Chinese scholars have a major interest in being part of the game. ${ }^{18}$

A symposium was held in November 2018 at Tsinghua University in Beijing to reflect on Chinese IR at forty. Participants offered an upbeat assessment of the achievements of Chinese international studies in terms of knowledge production and theoretical innovation and celebrated home-grown theoretical discourses in four subfields, namely international politics, international security, international political economy, and diplomatic studies. While acknowledging that through learning/borrowing and knowledge acquisition, disciplinary IR in China has significantly narrowed its knowledge gap, there is also unmistakable recognition of the limits of such learning and acquisition. Exhortations have been made for not only

\footnotetext{
14 Acharya, "Global International Relations," 647.

15 Yongjin Zhang, "Constructing a Chinese School of IR as a Sociological Reality: Intellectual Engagement and Knowledge Production," in Constructing a Chinese School of International Relations, eds. Yongjin Zhang and Teng-Chi Chang (London and New York: Routledge, 2016), 192-209.

16 Qin, "Development of International Relations".

17 Yongjin Zhang, "China and the Struggle for Legitimacy of a Rising Power," Chinese Journal of International Politics 8 no. 3 (2015): 301-22.

18 Acharya and Buzan, "Why Is There No Non-Western IR Theory?," 207.
} 
catching up with Western IR, but also 'transcending' it through theoretical innovation and new knowledge production in promoting disciplinary progress. The imperative has also been noted for the Chinese IR epistemic community to further emancipate the mind, and for the importance of participating in dialogue with global IR epistemic communities with an open mind. ${ }^{19}$

\section{The Chinese School of IR and Global Production of Knowledge}

Participants at the Tsinghua Symposium noted in particular a decisive and bold move from knowledge acquisition to knowledge production/creation in Chinese IR in the last fifteen years or so with coordinated efforts at intellectual creativity and with clear articulation of theoretical ambition. ${ }^{20}$ Symptomatic of this move from theoretical learning to theoretical contestation and innovation are the ongoing debates centred around the construction of a Chinese School of IR and on how China's own national experience, knowledge claims, and cultural heritage can and must be brought to bear upon the creative production of local knowledge about the 'international'.

Intellectually, Chinese debates on whether the distinctive national social experience of China should be taken into consideration in pursuit of constructing China's own international theory can be traced to the 1980s. It was at the first national conference on international relations theory in Shanghai in 1987 that the question of developing an IR theory 'with Chinese characteristics' was first raised. The call was arguably intuitive, mimicking 'socialism with Chinese characteristics' and it is mainly the politics of legitimation of the subject that was behind this call. More than twenty years later, similar calls-whether it is for developing an IR theory 'with Chinese characteristics', or for 'indigenizing IR in China', or for constructing 'a Chinese School of IR' - are no longer a reflection of just concerns for political legitimation. They are also backed up by intellectual justifications. They are consciously reflective of and driven by growing epistemic skepticism about the existing theoretical claims in Western IR and the intellectual discontent with their inability to explain the specific problems China is confronted with as it rises. At a national conference on IR theories held in Shanghai in 2004, an explicit call was issued for theoretical innovation, which would 'embody the Chinese characteristics, incorporate both Marxist international thought and the scientific core of Western IR theories, and cultivate the Chinese cultural heritage'. ${ }^{21}$ They amount to purposive contestations to, if not a revolt against, the dominance of Western IR theories and are expressive of the intent to make Chinese IR differently different.

If these attempts at theoretical innovation and contestations by Chinese scholars have led to a number of claims and hypes heralding the arrival a Chinese School of IR, it should be noted that assertions about the feasibility, inevitability or desirability of constructing such a School have also been and continues to be heavily contested. ${ }^{22}$ It is also noteworthy that

\footnotetext{
19 “A symposium on International Studies in China at Forty was held at Tsinghua University," Sohu Report 2018, http://www. sohu.com/a/277663669_618422; Yan, “"Academic Research”.

20 "A symposium on International Studies in China". 2006).

21 Yizhou Wang and Zhengqing Yuan, eds., International Studies in China, 1995- 2005 (Beijing: Peking University Press,

22 See Qin, "Why is There No Chinese IR Theory"; Qin, "Development of International Relations Theory in China"; Wang and Yuan, International Studies in China; Wang, "China: Between Copying and Constructing"; Nele Noesselt, "Mapping the World
} 
a self-consciously reflexive Chinese IR epistemic community has emerged and that battle cries and flag-waving are real in the construction of a Chinese School of IR. In one sense, the Chinese School of IR can perhaps best be characterized as a broader conversation or in Randall Collins' words 'coalitions in the mind' based on the shared belief in the possibility and desirability of constructing a Chinese School of IR and firm commitment to and strong interests in its construction. ${ }^{23}$ Rather than one homogenous school of thought, it is a conversation about how to theorise a distinct perspective on world politics that draws on Chinese cultural resources and is informed by a historically contingent situation of China's rise to a global power status. Through the geo-epistemic lens, the putative Chinese School is marked by profound disagreements among its advocates as to the agenda, the methodology, and the focus of empirical research for the Chinese School project, and its possible theoretical contribution to knowledge production. ${ }^{24}$ This is amply demonstrated in the four attempts at theoretical innovation by Chinese scholars discussed below. ${ }^{25}$ That said, it is these ongoing theoretical contestations among Chinese scholars and their critics and innovative production of IR scholarship centred around the construction of a Chinese School of IR that constitute one of the most contentious, arguably perhaps one of the most productive and also the most promising, non-Western sites of IR knowledge production.

Four cases of home-grown knowledge production and theoretical innovation by Chinese scholars have recently captured the attention and imagination of the global IR epistemic community. They are worth discussing briefly here. The first is Yan Xuetong's moral realism. It is closely associated with the so-called Tsinghua Approach (School) of International Relations, which refers to a distinctive research program carried out by Yan Xuetong and his team at the Institute of International Relations at Tsinghua University. It goes back to ancient Chinese history and philosophy to explore how ancient Chinese philosophers conceptualized power, authority, hegemony, war, order and justice and how morality informs interest. This is an exercise of archaeology of knowledge. Its purpose is to rediscover ancient Chinese international thought as an intellectual source for theoretical innovation. ${ }^{26}$ The publication of Ancient Chinese Thought and Modern Chinese Power by Princeton University in 2011 disseminated some findings of the research program beyond the Chinese IR epistemic community and attracted a lot of attention internationally. Yan is explicit about the possibility of 'creating a new IR theory on the basis of both ancient Chinese international thought and contemporary IR theory', i.e. Chinese historical data including thought can be made

from a Chinese Perspective? The Debate on Constructing a Theory of International Relations with Chinese Characteristics," China Quarterly 222 (2015): 430-48; Yongjin Zhang and Teng-Chi Chang, eds., Constructing a Chinese School of International Relations: Ongoing Debates and Sociological Realities (London and New York: Routledge, 2016).

23 Randall Collins, The Sociology of Philosophies: A Global Theory of Intellectual Change (Cambridge, MA: Belknap Press of Harvard University Press, 1998).

24 Yongjin Zhang and Peter Marcus Kristensen, "The Curious Case of "Schools" of IR: from Sociology to Geopolitics of Knowledge," Chinese Journal of International Politics 10, no. 4 (2017): 429-54.

${ }^{25}$ For example, Yan is a self-professed realist and methodological positivist and is sceptical of the feasibility and desirability of constructing a Chinese School of IR, whereas Qin is a leading constructivist and a most vocal advocate of Chinese School of IR.

${ }^{26}$ Feng Zhang, "The Tsinghua Approach and the Inception of Chinese Theories of International Relations," Chinese Journal of International Politics 5, no. 1 (2012): 73-102. 
meaningful by social scientific methodology to enrich contemporary IR theories. ${ }^{27}$ Such attempts at theoretical innovation have led Yan to produce what he terms 'moral realism,' as a distinct international relations theory. ${ }^{28}$

In the words of Yan, 'Moral realism is an international relations theory that deliberates how the political leadership of great powers determines the fate of their rise or fall, thus the structural change of the international system' ${ }^{29}$ Put differently, moral realism takes political leadership of great powers defined in terms of morality as the key variable in understanding the power transition integral in the systemic transformation of international relations. Such leadership can be categorized as inactive, conservative, proactive, or aggressive at the national level, and as tyranny, hegemony, and humane authority at the international level. Moral realism is therefore a binary theory which suggests that whereas a state's power defines its strategic interests, types of political leadership informed by moral considerations determine strategies for achieving those interests. For Yan, the central theoretical puzzle that moral realism must crack is why a rising state is able to displace a dominating hegemon even when it is inferior to the latter in terms of economic power, technological invention, education system, military strength, and political system. Yan claims that through the lens of moral realism, China will be able to change the international system in the $21^{\text {st }}$ century if it practices the moral principles of fairness, justice, and civility both at home and abroad. ${ }^{30}$ Yan's articulation of moral realism has been most systematically elaborated in his 2019 book Leadership and the Rise of Great Powers published by Princeton University Press. ${ }^{31}$

Second, is Qin Yaqing's construction of a relationality theory of world politics. Qin is a leading Chinese constructivist scholar, who translated Alex Wendt's Social Theory of International Politics into Chinese. Qin shares with Yan an aspiration for theoretical innovation by 'taking inspiration from Western theories and engaging them with Chinese culture, practices and worldviews'. ${ }^{32}$ Like Yan, Qin goes back to ancient Chinese philosophical tradition for inspiration. Qin's research project is, however, completely different from Yan's in important aspects. Qin aims to construct a theory of relationality (vis-à-vis rationality) to understand the dynamics of international relations by reinventing Confucian relationalism. That is to say, Qin takes the Chinese idea of 'relationality' as the hard core of his theoretical construct by giving 'relationship' ontological status, and theorizes it 'following social science principles', and more specifically those of social constructivism.

\footnotetext{
27 Xuetong Yan, Ancient Chinese Thought, Modern Chinese Power, ed. Daniel A. Bell and Sun Zhe, trans. Edmund Ryden (Princeton, NJ: Princeton University Press, 2011). It should be noted that Yan Xuetong and his Tsinghua associates are not the first, nor the only, group of Chinese scholars to explore ancient Chinese history and philosophy as valuable sources for the studies of international relations. Ye Zicheng of Peking University, for example, published his manuscript China's Diplomatic Thought during the Spring-Autumn and the Warring States Periods in Hong Kong in 2003. This was followed up in 2006 by an article co-authored with Wang Rihua on 'Schools of Diplomatic Thought during the Spring-Autumn and the Warring States Periods'. None of these previous works, however, makes an explicit claim of theoretical innovation or contribution to existing IR theories.

${ }^{28}$ Xuetong Yan, "An International Relations Theory of Moral Realism," International Studies 5 (2014): 102-28.

29 Yan, “An International Relations Theory," 102.

${ }^{30}$ Xuetong Yan, "Political Leadership and Power Redistribution," Chinese Journal of International Politics, 9, no. 1 (2016): $1-26$.

31 Xuetong Yan, Leadership and the Rise of Great Powers (Princeton, NJ: Princeton University Press, 2019).

32 Yaqing Qin, "Culture and Global Thought: Chinese International Theory in the Making," Revista CIDOB d'Afers Internacionals 100 (2012): 86.
} 
Qin insists that culture shapes all social theories as background knowledge and calls for constructing 'a multiverse of knowledge' of IR. ${ }^{33}$ This immediately provincializes Western IR and legitimizes his theoretical project. Qin is scathingly critical of individualistic rationalitybased IR theories for providing only one particular perspective in understanding and interpreting International Relations. For Qin, culture enables theoretical innovation. Digging deep into the background knowledge of Chinese thought and civilization, Qin's Relational Theory of World Politics published by Cambridge University Press in 2018 provides a theory at once contrasting and complementary to the existing (Western) IR theories. Qin sees non-Western IR (his own theoretical construction included) 'as significant dialog partners that reflect the reality of world politics and enrich the theoretical treasure house through knowledge production for a truly global IR project.' 34

In both instances above, there is an unequivocal struggle to bring the Chinese consciousness and Chinese sensibilities to theoretical innovation. Both projects are motivated by an explicit claim that Western IR theories are inadequate, and possibly deficient, without taking seriously Chinese experience, ideas and knowledge claims. However, it is also clear that even these bold moves to contest existing IR theories cannot escape from the prevailing theoretical tools, and they can hardly dispense with the dominant positivist epistemological and methodological assumptions. There is indeed hardly any intention to challenge these assumptions, which in fact inform and are embedded in the theoretical framing of both projects. After all, in so far as IR is part of the 'colonial expenses' of social sciences, there is an acute intellectual dilemma to wrestle with in Chinese (and probably any non-Western) intellectual attempts at knowledge production and theoretical innovation. That is that Western IR is both indispensable (largely because of the advantage of its head start) and inadequate (because of deeply entrenched Euro-centric bias).

Third is Tang Shiping, who is the winner 2015 ISAAnnual Best Book Award. In his awardwinning book The Social Evolution of International Politics published by Oxford University Press in 2013, Tang is scathingly critical of all the key grand theories of international politics, ranging from offensive realism, defensive realism, neoliberalism, to the English School and constructivism, in their failure to provide a genuinely endogenous explanation of the systemic transformation of international politics. The root problem for all these grand theories is, in his words, "the transformation power of time has been largely, if not completely, missing in all of the grand theories of international politics'. In his words, 'these three theories [i.e. offensive realism, defensive realism, neoliberalism/the English School] legitimate grand theories of international politics because they roughly capture three distinctive eras of international politics: a world that we had experienced; a world that we have been experiencing; and a world that we may be making' ${ }^{35}$ It follows that the transformation of international politics that SEP (social evolution paradigm) tries to explain is no different from that already embedded in

33 Yaqing Qin "A Multiverse of Knowledge: Cultures and IR Theories," Chinese Journal of International Politics 11, no. 4 (2018): 415-34.

34 Qin, "A Multiverse of Knowledge," 416.

35 Shiping Tang, The Social Evolution of International Politics (Oxford: Oxford University Press, 2013 ), 201. 
the grand historical narratives provided by those grand theories, which 'have been looking at roughly the same human history'. ${ }^{36}$ In macro-historical terms, the transformative history of international relations moves, in his words, 'from the initial paradise-like (but still selfhelp) anarchy to the "nasty, brutish, and short" Hobbesian (Mearsheimer's) offensive realism world, then to a Lockeian (Jervis's) defensive realism world, and then to a more rule-based world'. Tang's ambitious project seeks to advance the social evolution paradigm (SEP) as 'a powerful and indispensable paradigm for social sciences'. The SEP is superior, he suggests, to the existing grand theories, as it "not only provides genuinely endogenous explanations for the systemic transformations of international politics but also neatly resolves some of the great debates among IR theories'. ${ }^{37}$

Unlike Yan and Qin, Tang makes no effort to bring Chinese knowledge claims to his project, although there is extensive analytical engagement with empirical studies of Chinese history in both Chapters 2 and 3. For Tang, existing grand IR theories are inadequate, not because of their neglect of Chinese and non-Western experience and knowledge claims. It is rather because they have largely ignored the transformative potential of temporality in the evolution of the international system.

Finally, there is Zhao Tingyang, a Chinese philosopher. The philosophical intervention of Zhao Tingyang in Chinese IR theoretical debate and innovation was largely unanticipated but most productive in generating debates about how ancient Chinese history and philosophy as a critical resource could and should be drawn upon for innovative theorization of IR. It starts with the publication of his Tianxia Tixi (The System of All-under Heaven) in 2005. Zhao's works since 2005 have sought to advance a philosophical critique of the worldview prevailing in Western philosophy and IR theory. ${ }^{38}$ It is his sustained attack on the ontology and epistemology of Western political thought that inserts him in the meta- theoretical debate in the existing IR scholarship.

The key claim that Zhao has made is that today's world is a non-world, i.e. philosophically and institutionally it is not a world in its true sense. The only world that prevails today is a geographical one institutionally failed and politically abandoned. The ontological world understood and interpreted by Western philosophy is a problematic one because it is a world constituted by rational state actors, who pursue their narrow national interests. The world-ness of the world is sadly missing because Western political theory and international theory justify national interest in governing world politics, thus denying the world its worldness. The existing institutions created by and for powerful states do not promote universal wellbeing. ${ }^{39}$ 'The failure of world politics is essentially the failure of [Western] philosophy. ${ }^{{ }^{4}}$ The Kantian vision of perpetual peace and its modern incarnation (i.e. democratic peace),

\footnotetext{
36 Tang, The Social Evolution, 4.

37 Tang, The Social Evolution, 4-6.

38 Tingyang Zhao, "Redefining Political Concepts with Tianxia: Problems, Conditions and Methods," World Economics and Politics 6 (2015): 4-22; Tingyang Zhao, A Possible World of All-under-the-Heaven System: The World Order in the Past and for the Future (Beijing: Zhongxin Publishing House, 2016).

39 Tingyang Zhao, The System of Tianxia-All-under-Heaven: A Philosophy of World Institutions (Nanjing: Jiangsu Education Publishing House, 2005).

40 Tingyang Zhao, “A Political World Philosophy in terms of All-under-heaven (Tian-xia),” Diogenes 221 (2009): 7.
} 
for example, fail to transcend, let alone overcome, the cultural and spiritual divides among civilizations. The idea of a 'federation of free states', constructs insiders and outsiders in the world and does more to divide than unite the world. So does Western philosophy.

Zhao calls for 'a philosophical renewal of all-under-heaven' and argues for an imaginative and creative use of ancient Chinese political thought, particularly the idea of Tianxia (allunder-heaven) to foster an all-inclusive (or non- exclusive) worldview and to imagine a world that is of all and for all, where nothing is 'foreign' or 'pagan' ${ }^{41}$ 'Viewing the world as a whole is an epistemological principle first used by Laozi'. As Chinese philosophy always considers the world more as a political body than a scientific object, it is a political epistemology not a scientific one that informs ancient Chinese philosophy. 'Chinese philosophy deals more with the problems of relations (how close is this view to Qin's!) and the heart, whereas Western philosophy concentrates more on the truth and the mind. ${ }^{42}$ A global political philosophy constructed around the idea of Tianxia is to cultivate a worldview equivalent to, in his words, 'a mind at peace, free from the trap of thinking in terms of war, enemy, winner and loser. It is different as political mentality from those of Machiavelli, Hobbes, Marx, Freud, Schmitt, Morgenthau, and Huntington, and different in a practical sense from the hegemonic order of Pax Romana, Christian cosmopolitanism and democratic peace under US leadership. ${ }^{243}$ For Zhao, 'a philosophical renewal of all-under-heaven' is indispensable in search of such a global political philosophy. It entails 'rethinking China'; and 'the historical significance of "rethinking China" lies in recovering China's own ability to think'. ${ }^{44}$

Regardless of the contested nature of the claim of a Chinese School of IR, these four cases discussed above show beyond doubt that there have been conscious efforts by Chinese scholars at IR theoretical innovation in the last decade or so and that one can speak with confidence today of a distinctive Chinese contribution to global IR theoretical knowledge production. It should be also clear that they are very different in terms of epistemological claims made, methodological approaches adopted and their understandings of the purposes of theoretical pursuit articulated, even when they all (with the exception of Tang Shiping) conscientiously draw on ancient Chinese political and philosophical thought. It is heartening to see that these most notable Chinese contributions to global theoretical knowledge production have started to be recognized through publications by prestigious university presses such as Cambridge, Oxford and Princeton as mentioned above. Yet, the Chinese School labelling remains as contentious as ever in the existing core and periphery structure of global knowledge production, which remains largely intact. What does the school labelling then tell us about the geopolitics of knowledge and contentious politics in disciplinary IR?

\footnotetext{
${ }^{41}$ Zhao, "A Political World Philosophy," 9.

42 Zhao, "A Political World Philosophy," 10.

${ }^{43}$ Zhao, The System of Tianxia, 7.

44 Zhao, The System of Tianxia, 7.
} 


\section{4. 'School' Labelling and Contentious Politics In Disciplinary IR ${ }^{45}$}

If it is broadly accepted that all ideas and IR theories develop in a specific historical, social, cultural and geographical context, why is it that only some are labelled after specific geocultural/geographical sites such as the English School and the Chinese School, while others are simply called theories and paradigms? Why are 'isms', such as liberalism, realism, and constructivism, not considered part of a wider 'American School'? What does such labelling do, and what purposes does it serve? Why do labels matter? Answers to these questions depend contingently on the perspective from which one is speaking, the dominant and privileged core, or the marginalized and underprivileged peripheries of the discipline. They are closely related to geopolitics of knowledge and to the contentious politics behind the (epi)phenomenon of school labelling in the asymmetrical structures of knowledge dissemination and exchange.

For those sitting at the dominant and privileged core, School labelling has been used to serve for the following three purposes. In the first instance, there is a certain 'repressive tolerance' involved in the use of geographical and institutional labelling of schools of thought by the 'core'. It grants recognition of its existence, but not as a theory on a par with other (American) theories. It is not a pure coincidence that in a broader geopolitical pattern of the sociology of 'schools' in IR, such labels are conferred almost exclusively on international thought produced outside the United States. Theoretical knowledge produced in the American core is mostly referred to prestigiously as theories and paradigms, thus privileging theoretical knowledge produced in the United States as 'untainted' by its geocultural origins. This effectively creates parallel but hierarchical universes in the production of disciplinary knowledge. The labelling of geographical and institutional schools conveniently relegates them to a different and arguably inferior universe of knowledge production and circulation. It thus becomes an integral part of a strategy of 'dominance by neglect' by the core.

Secondly, for sceptics and critics at the core, a repressive use of the school label serves the purpose of singularizing and homogenizing ideas. It implies that all thought under the given geographical or institutional denominator can be described in singular terms. This serves to impose a greater degree of homogeneity within the school. Compared with American IR, which presents itself as pluralistic, these schools of thought would look hopelessly parochial and provincially monotonous. Yet, as demonstrated in earlier discussions of this paper, there is significant epistemological and methodological diversity within the Chinese School, even though the notion of a singular 'Chinese School' seems to suggest otherwise. Significant differences also exist between pluralism and solidarism in the English School, which can in part be attributed to different geo-epistemic positions privileging international society vis-àvis world society perspectives.

Thirdly, for the 'core', labelling schools of thought with a geographical and institutional prefix is useful for localizing ideas, thus denying their potential for developing a universal theory. The use of national labels by the core, such as Chinese, Indian, and Korean, has so far proved effective in localizing those theoretical noises from the peripheries, and

\footnotetext{
45 This part of the paper draws heavily from Zhang and Kristensen, "The Curious Case of "Schools"'.
} 
even in delegitimizing their counter-hegemonic protests against the dominance of the American 'core'. From the perspective characteristic of IR as an American social science, geographically labelled 'national' schools are invited into the global field only as 'schools' that are local, applicable solely to their particular geographical context, constructed and developed exclusively for their own nation-state, and perhaps only for the consumption of their nationals.

Clearly, school labelling affects how such theorizing efforts on the peripheries and semiperipheries may be invited into the conversation in the heartland of the discipline, i.e. their positionality in a globalized American social science. School labelling in this understanding has helped reinforce and reclaim the centrality of mainstream IR theories and the universality claims of the American 'core', as well as marginalizing, if not totally discrediting or delegitimizing, alternative approaches as inherently locally bounded.

If school labelling has been used by the core to reinforce its dominance as suggested above, why should school labelling have been so willingly appropriated by their proponents on the disciplinary peripheries, particularly in the non-Western IR epistemic communities? What particular strategic purposes has school labelling served in promoting theoretical innovation beyond the West?

For its proponents beyond the West, school labelling has been actively appropriated for three strategic and political reasons. First, geographical school-making on the peripheries carries special political significance and is purposely contentious. It is true that for some, particularly those advocating national schools, this is meant to assert a particular national identity through producing alternative theories. But for others, waving the flags of national schools of IR beyond the West is not aimed solely at alternative knowledge production. Rather, it is also a purposeful political contention, as many feminist, post-colonial and green battle cries have been. It serves to make a political point to disturb the status quo, to articulate a protest over the prevailing disciplinary fashion, and to engage in a kind of academic insurrection, or 'epistemic disobedience', in the words of Walter Mignolo, against the theoretical and intellectual hegemony of either its Eurocentrism reincarnation or an American social science manifestation. ${ }^{46}$

Secondly, the appropriation of national geographical school labels by those on the peripheries can be read as a strategic way to decentre and provincialize, perhaps even nationalize, American IR, and expose the self-serving interests of its pretentiously universalist epistemology. In asserting their legitimacy, emerging non-Western schools have often claimed to be counter-hegemonic, in particular against the dominance of American IR as an intricately differentiated structure of authorities that privileges a singular site for knowledge production with a particular conception of what is credible and legitimate knowledge. Looking through geo-cultural lenses, challenging the universalist claims of American IR theories through theoretical innovation by non-Western IR schools is to assert knowledge

46 Walter D. Mignolo, "Epistemic Disobedience, Independent Thought and De- Colonial Freedom," Theory, Culture \& Society 26, no. 7-8 (2009): 1-23. 
claims from the putative peripheries and semi-peripheries of the discipline in its existing geography of knowledge. It not only attempts to break down the prejudices embedded in the existing knowledge system, but also questions the claim of the American 'core' as the creator, depositor, and distributor of universal knowledge.

Thirdly, geographical school-making becomes an articulation of 'an epistemic awakening'. In highlighting the global power differential in the geopolitics of knowledge-making, it unveils the geo-historical linkage between the political and the epistemic. It lays bare the nature of the 'epistemic violence', as Gayatri Spivak would have it, historically committed by Eurocentrism 'understood as a way of conceiving of and organizing knowledge', which continues to obstruct and undermine 'Southern' or 'non-Western' approaches to knowledge. ${ }^{47}$ School labelling is political, as it is integral to a collective action to redress epistemic injustice which contributes to the oppression of those at the margins and their claims as knowers. ${ }^{48}$ From a sociology of knowledge stance, it is important to stress that this is primarily a move in disciplinary politics, not necessarily a product of great power politics, as the most externalist accounts, and many critics of new schools, would have it.

\section{Final Remarks}

The globality of IR as a discipline is unmistakable today. So is the global contribution to the production of knowledge of IR from multiple non-Western sites, as the discussions of the Chinese School of IR above demonstrate. From the perspective of contentious politics in disciplinary IR, non-Western school labelling and making constitutes an intervention into the uneven geopolitical structures of IR under the conditions of inequalities of power, as it calls into question the modern and colonial foundation of the control of knowledge while also creating an opening for alternative sources and foundations for theoretical pursuit and construction that are inclusive of a richer variety of voices, experiences and knowledge claims. In that sense, IR knowledge production from multiple non-Western sites should be celebrated as an important step towards constructing a truly global IR.

\section{Bibliography}

Acharya, Amitav. "Global International Relations (IR) and Regional Worlds: A New Agenda for International Studies.” International Studies Quarterly 58, no. 4 (2014): 647-59.

Acharya, Amitav, and Barry Buzan. "Why is there no Non-Western International Relations Theory? Ten years on." International Relations of the Asia- Pacific 17, no. 3 (2017): 341-70.

Acharya, Amitav, and Barry Buzan. "Why Is There No Non-Western IR Theory?" International Relations of the Asia-Pacific 7, no. 3 (2007): 287-312.

Collins, Randall. The Sociology of Philosophies: A Global Theory of Intellectual Change. Cambridge, MA: Belknap Press of Harvard University Press, 1998.

Deng, Xiaoping. Selected Works of Deng Xiaoping, Volume II. Beijing: People"s Publishing House, 1994. Fricker, Miranda. Epistemic Injustice: Power and the Ethics of Knowing. Oxford: Oxford University Press, 2007. MaGann, James G. “2018 Global Go To Think Tank Index Report.”2019. https://repository.upenn.edu/think $\operatorname{tanks} / 16 /$.

47 Walter. D. Mignolo, "The Geopolitics of Knowledge and the Colonial Difference," The South Atlantic Quarterly 101, no. 1 (2002): 84 .

${ }^{48}$ Miranda Fricker, Epistemic Injustice: Power and the Ethics of Knowing (Oxford: Oxford University Press, 2007). 
Mignolo, Walter D. "Epistemic Disobedience, Independent Thought and De- Colonial Freedom." Theory, Culture \& Society 26, no. 7-8 (2009): 1-23.

—. "The Geopolitics of Knowledge and the Colonial Difference." The South Atlantic Quarterly 101, no. 1 (2002): 57-96.

Noesselt, Nele. "Mapping the World from a Chinese Perspective? The Debate on Constructing a Theory of International Relations with Chinese Characteristics." China Quarterly 222 (2015): 430-48.

Porter, Brian, ed. Aberystwyth Papers: International Politics, 1919-69. Oxford: Oxford University Press, 1972.

Qin, Yaqing. "A Chinese School of International Relations Theory: Possibility and Inevitability.” World Economics and Politics 3 (2006): 7-13.

—. "Culture and Global Thought: Chinese International Theory in the Making." Revista CIDOB d"Afers Internacionals 100 (2012): 67-90.

—. "Development of International Relations Theory in China: Progress through Debates." International Relations of the Asia-Pacific 11, no. 2 (2011): 231-57.

—. "A Multiverse of Knowledge: Cultures and IR Theories." Chinese Journal of International Politics 11, no. 4 (2018): 415-34.

—. A Relational Theory of World Politics. Cambridge: Cambridge University Press, 2018.

—. "Why is There No Chinese IR Theory." International Relations of the Asia-Pacific 7, no. 3 (2007): 313-40.

Shambaugh, David. "International Relations Studies in China Today: History, Trends and Prospects." International Relations of the Asia-Pacific 11, no. 3 (2011): 339-72.

Sohu Report . "A symposium on International Studies in China at Forty was held at Tsinghua University." 2018. http://www.sohu.com/a/277663669_618422.

Sun, Jisheng. "IR Theoretical Development in China since the Beginning of Economic Reform and Opening: Discourses, Practices and Innovation." World Economics and Politics 8 (2018): 4-29.

Tang, Shiping. The Social Evolution of International Politics. Oxford: Oxford University Press, 2013.

Tickner, Arlene, and David Blaney, eds. Thinking International Relations Differently. London and New York: Routledge, 2012.

Tickner, Arlene, and Ole Waever, eds. International Relations Scholarship around the World. London and New York: Routledge, 2009.

Tilly, Charles, and Sidney Tarrow. Contentious Politics. Oxford: Oxford University Press, 2015.

Waever, Ole. "The Sociology of a Not So International Discipline: American and European Developments of International Relations.” International Organization 52, no. 4 (1998): 687-727.

Wang, Yiwei. "China: Between Copying and Constructing." In Tickner and Waever, International Relations Scholarship around the World 103-19.

Wang, Yizhou, and Yuan, Zhengqing, eds. International Studies in China, 1995- 2005. Beijing: Peking University Press, 2006.

Yan, Xuetong. "Academic Research on International Relations in the Last Forty Years since the Beginning of Economic Opening and Reform.” 2018. http://www.aisixiang.com/data/114932.html.

—. Ancient Chinese Thought, Modern Chinese Power. Edited by Daniel A Bell and Sun Zhe. Trasnlated by Edmund Ryden. Princeton, NJ: Princeton University Press, 2011.

_. “An International Relations Theory of Moral Realism.”International Studies 5 (2014): 102-28.

—. Leadership and the Rise of Great Powers. Princeton, NJ: Princeton University Press, 2019.

—. "Political Leadership and Power Redistribution." Chinese Journal of International Politics 9, no. 1 (2016): $1-26$.

Zhang, Feng. "The Tsinghua Approach and the Inception of Chinese Theories of International Relations." Chinese Journal of International Politics 5, no. 1 (2012): 73-102.

Zhang, Yongjin. China in International Society since 1949: Alienation and Beyond. Basingstoke: Palgrave, 1998.

__. "China and the Struggle for Legitimacy of a Rising Power." Chinese Journal of International Politics 8, no. 3 
(2015): 301-22.

—. "Constructing a Chinese School of IR as a Sociological Reality: Intellectual Engagement and Knowledge Production.” In Zhang and Chang, Constructing a Chinese School of International Relations, 192-209.

Zhang, Yongjin, and Peter Marcus Kristensen. "The Curious Case of "Schools" of IR: from Sociology to Geopolitics of Knowledge." Chinese Journal of International Politics 10, no. 4 (2017): 429-54.

Zhang, Yongjin, and Teng-Chi Chang, eds. Constructing a Chinese School of International Relations: Ongoing Debates and Sociological Realities. London and New York: Routledge, 2016.

Zhao, Tingyang. "All-Under-Heaven and Methodological Relationism: An Old Story and New World Peace.”In Contemporary Chinese Political Thought, edited by Fred Dallmayr and Zhao Tingyang, 46-66. Lexington: The University of Kentucky Press, 2012.

—. "A Political World Philosophy in terms of All-under-heaven (Tian-xia)." Diogenes 221 (2009): 5-18.

—. A Possible World of All-under-the-Heaven System: The World Order in the Past and for the Future. Beijing: Zhongxin Publishing House, 2016.

- "Redefining Political Concepts with Tianxia: Problems, Conditions and Methods." World Economics and Politics 6 (2015): 4-22.

- The System of Tianxia-All-under-Heaven: A Philosophy of World Institutions. Nanjing: Jiangsu Education Publishing House, 2005. 